Case Report

\title{
12q14 Microdeletions: Additional Case Series with Confirmation of a Macrocephaly Region
}

\author{
Adrian Mc Cormack, ${ }^{1}$ Cynthia Sharpe, ${ }^{2}$ Nerine Gregersen, ${ }^{3}$ Warwick Smith, ${ }^{4}$ \\ Ian Hayes, ${ }^{3}$ Alice M. George, ${ }^{1}$ and Donald R. Love ${ }^{1}$ \\ ${ }^{1}$ Diagnostic Genetics, LabPLUS, Auckland City Hospital, P.O. Box 110031, Auckland 1148, New Zealand \\ ${ }^{2}$ Department of Neuroservices, Starship Children's Health, Private Bag 92024, Auckland 1142, New Zealand \\ ${ }^{3}$ Genetic Health Service New Zealand-Northern Hub, Auckland City Hospital, Private Bag 92024, Auckland 1142, New Zealand \\ ${ }^{4}$ Middlemore Hospital, Private Bag 93311, Otahuhu, Auckland 1640, New Zealand
}

Correspondence should be addressed to Donald R. Love; donaldl@adhb.govt.nz

Received 16 April 2015; Revised 7 July 2015; Accepted 7 July 2015

Academic Editor: Patrick Morrison

Copyright (C) 2015 Adrian Mc Cormack et al. This is an open access article distributed under the Creative Commons Attribution License, which permits unrestricted use, distribution, and reproduction in any medium, provided the original work is properly cited.

To date, there have been only a few reports of patients carrying a microdeletion in chromosome 12q14. These patients usually present with pre- and postnatal growth retardation, and developmental delay. Here we report on two additional patients with both genotype and phenotype differences. Similar to previously published cases, one patient has haploinsufficiency of the HMGA2 gene and shows severe short stature and developmental delay. The second patient is only one of a handful without the loss of the HMGA2 gene and shows a much better growth profile, but with absolute macrocephaly. This patient's deletion is unique and hence defines a likely macrocephaly locus that contributes to the general phenotype characterising the 12q14 syndrome.

\section{Introduction}

Microarray technology has revolutionised the detection of human chromosomal abnormalities within cytogenetics by discovering new, as well as refining, existing syndromes. The technology has recently revealed the existence of a previously unknown deletion syndrome at $12 \mathrm{q} 14$. Initial case series have helped categorise and partially refine the genotype and phenotype correlations of this emerging syndrome [1-5], Table 1.

Menten et al. [2] investigated the causative gene for Osteopoikilosis using microarray technology and were the first to report three unrelated patients with de novo deletions of 12q14. Patients carrying heterozygous deletions in this region exhibited a common phenotype that included failure to thrive, short stature, and learning difficulties, which was noted to be phenotypically similar to Silver-Russell Syndrome (SRS). SRS is characterized by a variable clinical spectrum of pre- and postnatal growth retardation, relative macrocephaly, body asymmetry, and triangle facial gestalt $[6,7]$. It is mainly caused by two mechanisms: maternal UPD chromosome 7 or hypomethylation at the imprinting centre region 1 (ICR1) on 11p15 [6, 7]. Generally, patients who fulfil specific clinical criteria can be reliably diagnosed with SRS; however, for $50 \%$ of patients the etiology is unknown and these patients are often referred to as having an "SRS-like" phenotype [7]. Of these patients, those with deletions in the 12q14 region form a subgroup.

The 12q14 interstitial deletions found in these initial cases encompassed two critical genes: LEMD3 and HMGA2. Mutations in the former gene are implicated in Osteopoikilosis, while mutations in the latter gene in mice have a strong influence on height $[8,9]$. Mari et al. [5] confirmed the role of HMGA2 haploinsufficiency in the etiology of short stature and failure to thrive in reporting patients with deletions of this gene. A further case series reported by Buysse et al. [1] described patients without Osteopoikilosis, despite the loss of LEMD3 gene, and confirmed that heterozygous intragenic deletions of HMGA2 have a significant effect on human height. They proposed a minimum region of overlap 


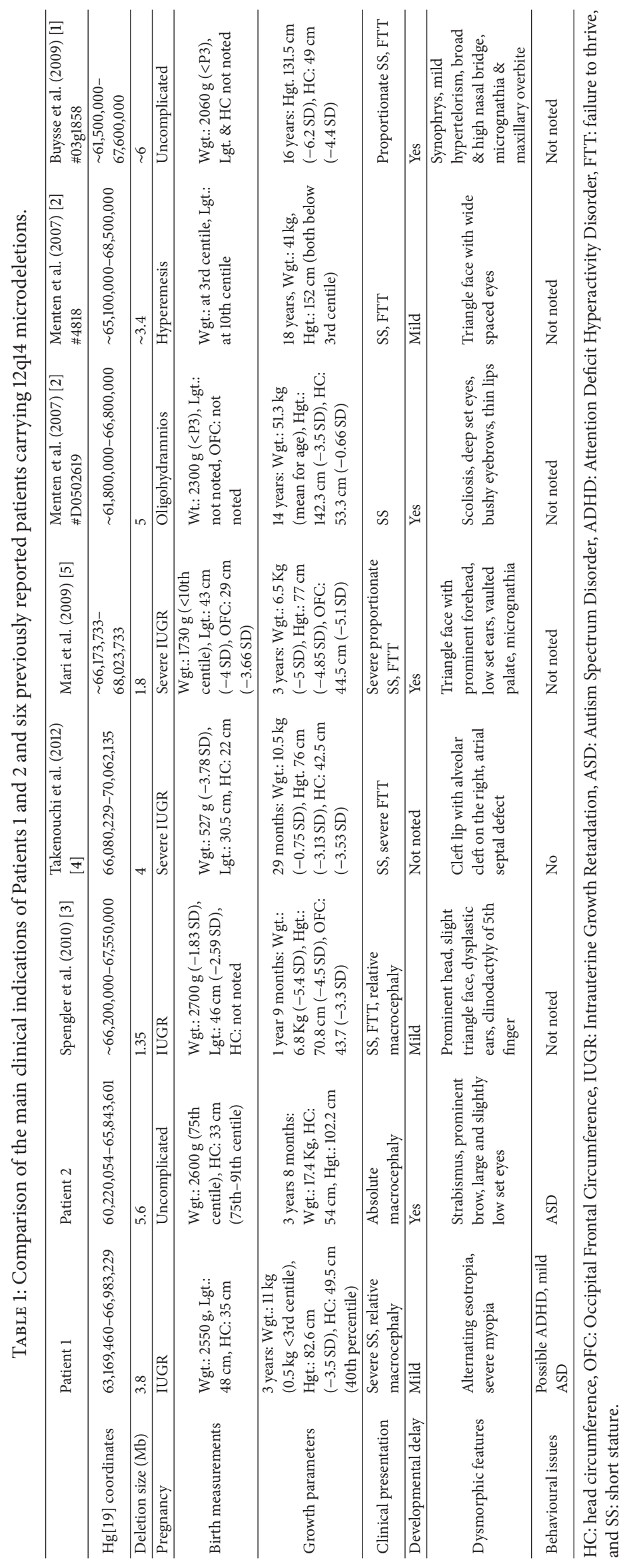


encompassing approximately 11 genes that were thought to play a role in patients manifesting 12 q14 microdeletion syndrome. Finally Takenouchi et al. [4] examined the correlation between the location (and extent) of deletions in 12q14 and clinical phenotype and proposed that relative macrocephaly may involve deletions upstream of the HMGA2 gene.

The study described here comprises an additional two patients with interstitial 12q14 microdeletions. Patient 1 carries a $3.8 \mathrm{Mb}$ heterozygous deletion involving the interstitial region $12 \mathrm{q} 14.2 \mathrm{q} 14.3$, and Patient 2 carries a $5.6 \mathrm{Mb}$ heterozygous deletion involving the interstitial region 12q14.1q14.3.

\section{Clinical Report}

2.1. Patient 1. A healthy male was born at 41-week gestation with asymmetrical growth restriction weighing $2550 \mathrm{~g}$ (<3rd centile), with length $48 \mathrm{~cm}$ (20th centile) and head circumference $35 \mathrm{~cm}$ (50th centile). The mother is a hyperactive, verbally aggressive and difficult individual who drank excessively during the pregnancy. She is also relatively short with a height of approximately $153 \mathrm{~cm}$ and has a strabismus. The father is approximately $183 \mathrm{~cm}$ tall, cannot read or write, and is socially reclusive. There were no concerns about the child's motor skills and achieved expected milestones. He was noted to be a behaviourally difficult child, always on the go, demanding attention, and seemingly always talking. He understood language and could talk well although at times his speech was unclear and he spoke in an unusual voice.

Paediatric assessment of the proband at three years of age noted that he was short, with height $82.6 \mathrm{~cm}$ (3.5 SD below the mean), weight $11 \mathrm{~kg}(0.5 \mathrm{~kg}$ less than the $3 \mathrm{rd}$ percentile), and head circumference $49.5 \mathrm{~cm}$ (on the 40 th percentile). He had deep set eyes and a thin upper lip but normal philtrum and palpebral fissures each $22 \mathrm{~mm}$ (-2 SD). He wore glasses suggesting severe myopia and manifested alternating esotropia. He had no clear features of Fetal Alcohol Syndrome, but there were concerns over possible mild dysmorphic features. It was noted that social communication was poor and that he talked in unusual voice prosody, with reasonable receptive and expressive language. He was diagnosed with mild Autism Spectrum Disorder (ASD), was hyperactive and aggressive, and had many features of ADHD. A final genetics consultation at four years of age confirmed previous findings and his guardians stated that he had problems with fine motor skills. Head circumference was near the 50th centile and height below the $3 \mathrm{rd}$ centile. He had the appearance of relative macrocephaly but little else to see from a dysmorphology perspective. The child never had X-rays so we cannot say if there were skeletal changes consistent with a diagnosis of Osteopoikilosis.

2.2. Patient 2. A female was delivered at 35-week gestation following a breech presentation. Family medical history was unremarkable. Birth head circumference was $33 \mathrm{~cm}$ (75th91st percentile for 35-week gestation), birth weight was $2.6 \mathrm{~kg}$ (75th percentile), and she had some issues with poor feeding. By 2 months of age her head had grown to $38.5 \mathrm{~cm}$ on the $98 \mathrm{th}$ percentile for her corrected gestational age and accelerated further to the 99th percentile by 6 months of age.

She passed her developmental screen at one year of age but a further assessment at 19 months revealed developmental delay. Macrocephaly was also first noted at this visit. Her head circumference has been stable $1-2 \mathrm{~cm}$ above the 98th percentile since then. Her motor skills were delayed and speech was also delayed and she met the criteria for ASD. She received speech therapy for six months, but this was stopped because at three years of age she had hundreds of words, was speaking in 2-3-word phrases, and understood most of what was said.

An MRI was performed at 27 months of age showing mild hyperintensity in the deep white matter in the periventricular regions of the occipital area bilaterally, more so on the right. There was no mass effect and the brain was normally formed, with no hydrocephalus noted.

Further paediatric examination at 3 years 8 months of age showed height of $102.2 \mathrm{~cm}$ (75th centile), weight of $17.4 \mathrm{~kg}$ (75-90th centile), and head circumference of $54 \mathrm{~cm}(+3.5$ $\mathrm{SD})$. There were no obvious dysmorphic features or neurocutaneous stigmata and she was undergoing treatment for a strabismus. She had evidence of both gross motor/fine motor and language delay but was showing excellent catching up of her development with appropriate inputs. Her last review at 4 years 5 months showed that her head circumference continued to track above the centiles at $55 \mathrm{~cm}$; she was $108 \mathrm{~cm}$ tall (75-90th centile) and weighed $20 \mathrm{~kg}$ (90th centile). She still met the criteria for a diagnosis of ASD and had global gross motor/fine motor and language delay but was showing very encouraging improvements in all aspects of her development. It was noted that she had mild plagiocephaly, a prominent brow, and mild hypertelorism (Figure 1(b)). The patient does not exhibit Osteopoikilosis, but she may be too young to manifest symptoms. The patient proved negative for mutations in the PTEN gene (by both dosage and sequencing), which was performed in light of macrocephaly and the diagnosis of autism.

2.3. Molecular Studies. DNA was extracted from both Patients 1 and 2 with genome-wide copy number analysis determined using an Affymetrix Cytogenetics WholeGenome 2.7M array and CytoScan 750K Array, respectively, according to the manufacturer's instructions. Regions of copy number change were determined using the Affymetrix Chromosome Analysis Suite software (ChAS) either v.1.0.1 or v.1.2.2 and interpreted with the aid of the UCSC genome browser (http://genome.ucsc.edu/; Human March 2006 (hg18) assembly or February 2009 GRCh37/hg19 assembly), Figure 2.

Patient 1 carried a $3.8 \mathrm{Mb}$ heterozygous deletion involving the interstitial chromosome region 12q14.2q14.3 (hg19 coordinates 63,169,460-66,983,229) encompassing 16 OMIM genes (AVPR1A, DPY19L2, TMEM5, SRGAP1, XPOT, TBK1, RASSF3, GNS, TBC13D0, WIF1, LEMD3, MSRB3, HMGA2, $I R A K 3, H E L B$, and part of GRIP1). Patient 2 carried a $5.6 \mathrm{Mb}$ heterozygous deletion involving the interstitial chromosome region 12q14.1q14.3 (hg19 coordinates 60,220,054-65,843,601) 


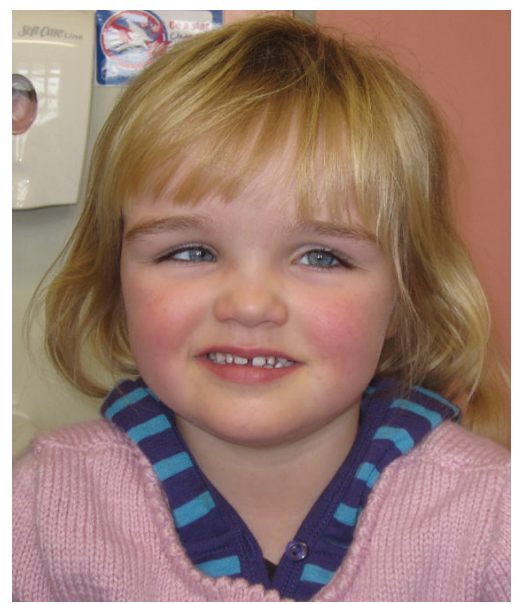

(a)

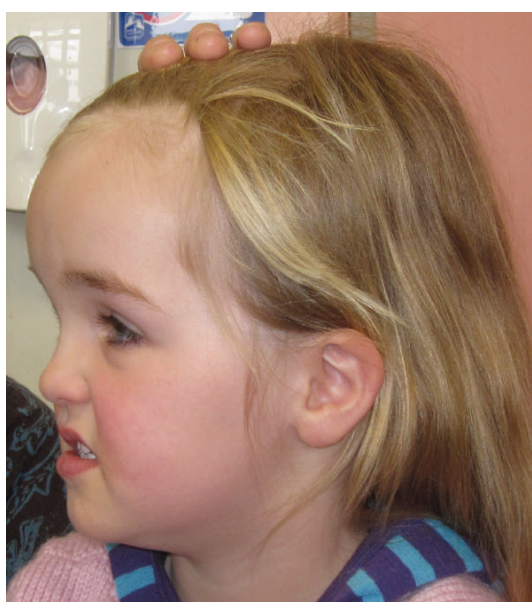

(b)

FIgure 1: (a) Image of Patient 2. (b) Patient 2 exhibits frontal bossing and macrocephaly.
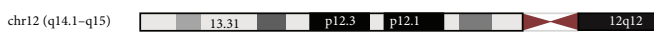

(a)
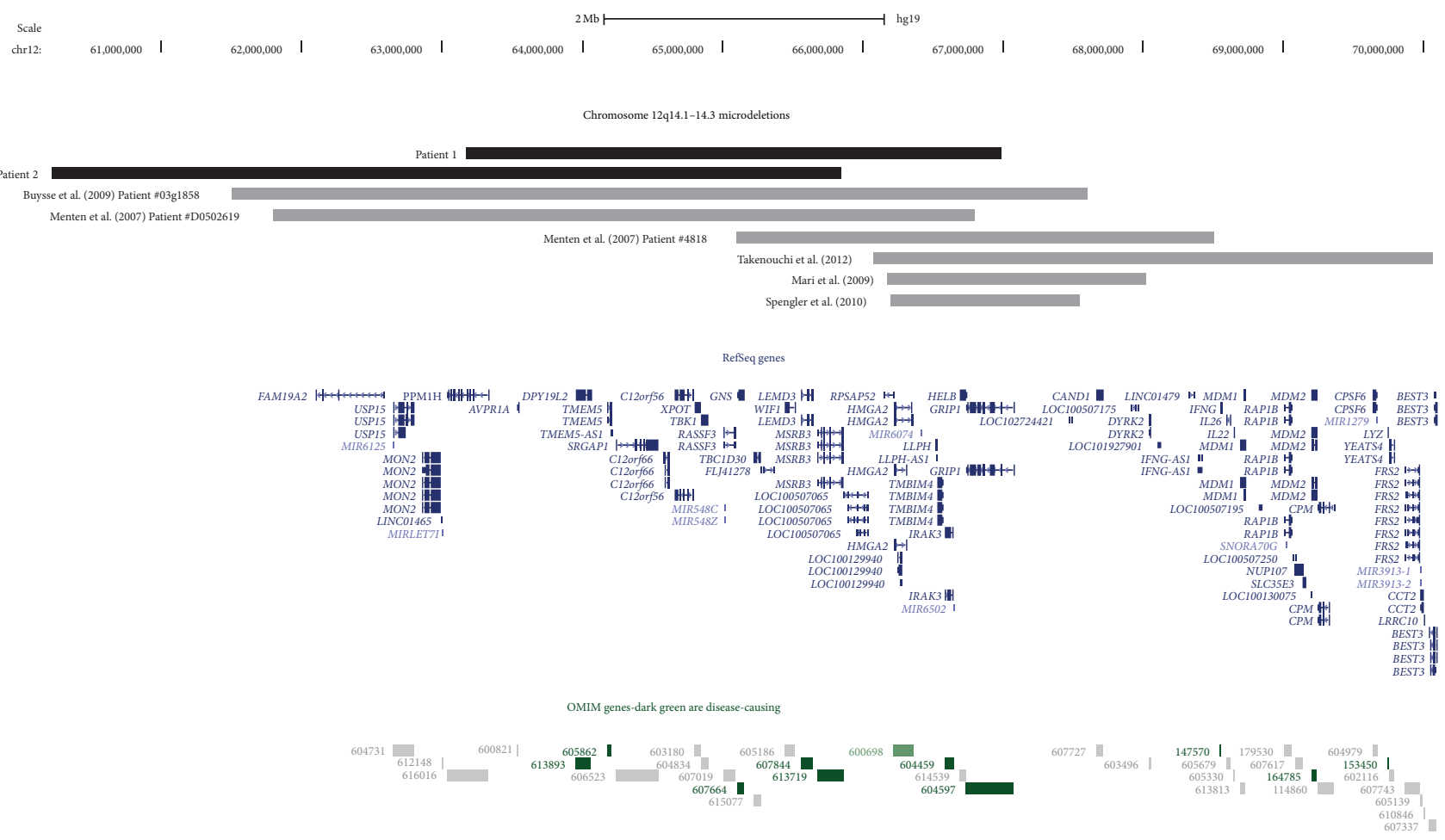

(b)

FIGURE 2: Schematic of chromosome 12q14 containing microdeletions. (a) shows an ideogram of chromosome 12. (b) shows the location and extent of the deletions detected in the patients described here and other cases reported in the literature, as well as RefSeq and OMIM genes that lie within 12q14. These graphics were taken from the UCSC genome browser (http://genome.ucsc.edu/).

encompassing 14 OMIM genes (USP15, MIRLET7I, AVPR1A, DPY19L2, TMEM5, SRGAP1, XPOT, TBK1, RASSF3, GNS, TBC1D30, WIF1, LEMD3, and part of MSRB3). The parents of Patient 1 were unavailable for follow-up analysis while the parents of Patient 2 showed normal molecular karyotypes.

\section{Discussion}

In the study described here, we report two patients with overlapping deletions in 12q14: a 3.8 Mb deletion in Patient 1 with extreme short stature, mild autism, behavioural problems, 
TABLE 2: OMIM genes that lie in the 12q14 interval bounded by USP15 and MSRB3.

\begin{tabular}{|c|c|c|}
\hline Gene & OMIM & Description \\
\hline USP15 & 604731 & $\begin{array}{l}\text { USP15 is required for TGFB and BMP responses in both mammalian cells and frog embryos. } \\
\text { The USP15 gene encodes for a deubiquitinating enzyme. Animal models have shown that it } \\
\text { regulates bone morphogenetic signalling during embryogenesis [10]. }\end{array}$ \\
\hline PPM1H & 616016 & Knockdown of PPM1H significantly increases proliferation in BT474 breast cancer cells [11]. \\
\hline AVPR1A & 600821 & $\begin{array}{l}\text { The AVPR1A gene encodes for a receptor that is involved in vasopressin signalling, which is } \\
\text { involved in behavioural responses, including stress management and territorial aggression } \\
\text { as well as social bonding and recognition [12]. }\end{array}$ \\
\hline DPY19L2 & 613893 & DPY19L2 represents the major gene causing globozoospermia [13]. \\
\hline TMEM5 & 605862 & $\begin{array}{l}\text { The TMEM5 gene encodes for a type II membrane protein of unknown function, but } \\
\text { mutations have been associated with gonadal dysgenesis, neural tube defects, and most } \\
\text { recently being a cause of severe cobblestone lissencephaly [14]. }\end{array}$ \\
\hline SRGAP1 & 606523 & $\begin{array}{l}\text { SRGAP1 interacts with Roundabout transmembrane receptors, together with SLIT proteins, } \\
\text { which guide neuronal and leukocyte migration [15]. }\end{array}$ \\
\hline XPOT & 603180 & Exportin-t is a specific mediator of tRNA export $[16,17]$. \\
\hline TBK1 & 604834 & TBK1 is a binding partner for optineurin [18]. \\
\hline RASSF3 & 607019 & The RASSF3 gene encodes for a putative tumor suppressor [19]. \\
\hline GNS & 607664 & $\begin{array}{l}\text { The GNS gene encodes for N-acetylglucosamine-6-sulfatase, which is required for } \\
\text { degradation of heparin sulphate. Homozygous mutations in this gene have been shown to be } \\
\text { the cause of mucopolysaccharidosis type IIID [20]. }\end{array}$ \\
\hline TBC1D30 & 615077 & TBC1D30 protein is predicted to be involved in cell signalling [21]. \\
\hline WIF1 & 605186 & $\begin{array}{l}\text { WIF1 binds to WNT proteins and inhibits their extracellular signaling involved in the } \\
\text { control of embryonic development [22]. }\end{array}$ \\
\hline LEMD3 & 607844 & $\begin{array}{l}\text { LEMD3 is involved in both BMP and TGF-beta signalling. Heterozygous loss-of-function } \\
\text { mutations in the LEMD3 gene are implicated in Osteopoikilosis and the associated } \\
\text { Buschke-Ollendorff syndrome [8]. }\end{array}$ \\
\hline$M R S B 3$ & 613719 & $\begin{array}{l}\text { The MSRB3 gene encodes for methioinine sulfoxide reductase. Homozygous mutations in } \\
\text { this gene are associated with a form of autosomal recessive, nonsyndromic deafness [23]. }\end{array}$ \\
\hline
\end{tabular}

Those genes in bold italics are implicated in bone morphogenesis.

TGFB: Transforming Growth Factor Beta.

BMP: Bone Morphogenetic Protein.

severe myopia, and esotropia and a 5.6 Mb deletion in Patient 2 with absolute macrocephaly, developmental delay, learning difficulties, and autism. The deletion in Patient 1 includes both the LEMD3 and HMGA2 genes, while the deletion in Patient 2 includes the LEMD3 gene but not the HMGA2 gene. The mother of Patient 1, who has short stature, behavioural issues, and a convergent strabismus, may also harbour a deletion, but unfortunately she was not available for testing to confirm this. Patient 2 had a de novo deletion.

Of the reported 12q14 interstitial deletion cases, only 5 (including one of the cases presented here) have not included the HMGA2 gene. The deleted region detected in Patient 1 includes the HMGA2 gene and this patient shows prenatal IUGR and severe short stature but critically the deleted region in Patient 2 does not encompass the HMGA2 gene and they exhibit no pre- or postnatal growth issues. Both cases reinforce the importance of the HMGA2 gene's influence on growth.

The HMGA2 gene (OMIM 600698) encodes a mammalian high mobility group (HMG) protein which is implicated in transcriptional regulation [24]. Ligon et al. [25] described a de novo pericentric inversion in an 8-year-old boy causing an intragenic rearrangement which truncated the HMGA2 gene, altering its expression and causing a phenotype which included overgrowth and lipomas. Interestingly, hmga 2-/- mice show a "pygmy" phenotype with short stature and reduction in body fat [9]. Buysse et al. [1] reported a small intragenic deletion of the HMGA2 gene in a boy with proportionate short stature, segregating within a larger pedigree with reduced adult height. In addition, Mari et al. [5] described a patient with a $1.84 \mathrm{Mb}$ deletion encompassing six genes including the $H M G A 2$ gene in which the phenotype comprised pre- and postnatal growth restrictions and short stature.

Critically, Spengler et al. [3] proposed a separate locus distinct from HMGA2 as being partially responsible for the SRS-like phenotype. Takenouchi et al. [4] reviewed deletions at 12q14 and showed that only a small group of patients had relative macrocephaly and short stature. They proposed two discernible groups of phenotypes of 12q14 microdeletions: a group of patients with short stature with relative macrocephaly and a group with an SRS-like phenotype and short stature without macrocephaly. They suggested a presumptive interval for relative macrocephaly spanning $0.5 \mathrm{Mb}-2 \mathrm{Mb}$, but not including the HMGA2 gene.

Patient 1, whose deletion includes the HMGA2 gene, appears to have an SRS-like phenotype. Interestingly, Patient 2 lacks a growth retardation phenotype but has absolute 
macrocephaly confirming the suggestion made by Takenouchi et al. [4] of a macrocephaly locus that contributes to the SRS-like phenotype for patients with deletions in 12q14. At this time, the function of only some of the genes located in the deleted interval detected in Patient 2 has been characterised, Table 2.

Our cases, together with those reported earlier, suggest that the SRS-like phenotype of patients with deletions in 12q14 can be refined to the following:

(1) Deletions that include (all or some of) the HMGA2 gene correlate with a growth-based phenotype.

(2) A macrocephaly region ( $2 \mathrm{MB}$ in length) proximal and independent of the HMGA2 gene correlates with an absolute macrocephaly phenotype (see Patient 2).

(3) Deletions involving both of these regions combine to form an SRS-like phenotype (see Patient 1).

In the future, smaller deletions within 12 q14 may be uncovered in order to narrow down a macrocephaly locus. Of the genes described above, the most likely candidate gene appears to be USP15 (see Table 2) because of its involvement in bone morphogenesis.

\section{Conflict of Interests}

The authors declare that there is no conflict of interests regarding the publication of this paper.

\section{References}

[1] K. Buysse, W. Reardon, L. Mehta et al., "The 12q14 microdeletion syndrome: additional patients and further evidence that HMGA2 is an important genetic determinant for human height," European Journal of Medical Genetics, vol. 52, no. 2-3, pp. 101-107, 2009.

[2] B. Menten, K. Buysse, F. Zahir et al., "Osteopoikilosis, short stature and mental retardation as key features of a new microdeletion syndrome on 12q14," Journal of Medical Genetics, vol. 44, no. 4, pp. 264-268, 2007.

[3] S. Spengler, N. Schönherr, G. Binder et al., "Submicroscopic chromosomal imbalances in idiopathic Silver-Russell syndrome (SRS): the SRS phenotype overlaps with the 12q14 microdeletion syndrome," Journal of Medical Genetics, vol. 47, no. 5, pp. 356360, 2010.

[4] T. Takenouchi, K. Enomoto, T. Nishida et al., "12q14 microdeletion syndrome and short stature with or without relative macrocephaly," The American Journal of Medical Genetics. Part A, vol. 158, no. 10, pp. 2542-2544, 2012.

[5] F. Mari, P. Hermanns, M. L. Giovannucci-Uzielli et al., "Refinement of the 12q14 microdeletion syndrome: primordial dwarfism and developmental delay with or without osteopoikilosis," European Journal of Human Genetics, vol. 17, no. 9, pp. 1141-1147, 2009.

[6] T. Eggermann, D. Gonzalez, S. Spengler, M. Arslan-Kirchner, G. Binder, and N. Schönherr, "Broad clinical spectrum in Silver-Russell syndrome and consequences for genetic testing in growth retardation," Pediatrics, vol. 123, no. 5, pp. e929-e931, 2009.
[7] S. Fokstuen and D. Kotzot, "Chromosomal rearrangements in patients with clinical features of Silver-Russell syndrome," American Journal of Medical Genetics, Part A, vol. 164, no. 6, pp. 1595-1605, 2014.

[8] J. Hellemans, O. Preobrazhenska, A. Willaert et al., "Lossof-function mutations in LEMD3 result in osteopoikilosis, Buschke-Ollendorff syndrome and melorheostosis," Nature Genetics, vol. 36, no. 11, pp. 1213-1218, 2004.

[9] X. Zhou, K. F. Benson, H. R. Ashar, and K. Chada, "Mutation responsible for the mouse pygmy phenotype in the developmentally regulated factor HMGI-C," Nature, vol. 376, no. 6543, pp. 771-774, 1995.

[10] L. Herhaus, M. A. Al-Salihi, K. S. Dingwell et al., "USP15 targets ALK3/BMPR1A for deubiquitylation to enhance bone morphogenetic protein signalling," Open Biology, vol. 4, no. 5, Article ID 140065, 2014.

[11] S. T. Lee-Hoeflich, T. Q. Pham, D. Dowbenko et al., "PPM1H Is a p27 phosphatase implicated in trastuzumab resistance," Cancer Discovery, vol. 1, no. 4, pp. 326-337, 2011.

[12] R. Charles, T. Sakurai, N. Takahashi et al., "Introduction of the human AVPR1A gene substantially alters brain receptor expression patterns and enhances aspects of social behavior in transgenic mice," Disease Models \& Mechanisms, vol. 7, no. 8, pp. 1013-1022, 2014.

[13] E. Elinati, P. Kuentz, C. Redin et al., "Globozoospermia is mainly due to dpy1912 deletion via non-allelic homologous recombination involving two recombination hotspots," Human Molecular Genetics, vol. 21, no. 16, pp. 3695-3702, 2012.

[14] S. Vuillaumier-Barrot, C. Bouchet-Séraphin, M. Chelbi et al., "Identification of mutations in TMEM5 and ISPD as a cause of severe cobblestone lissencephaly," American Journal of Human Genetics, vol. 91, no. 6, pp. 1135-1143, 2012.

[15] K. Wong, X.-R. Ren, Y.-Z. Huang et al., "Signal transduction in neuronal migration: roles of GTPase activating proteins and the small GTPase Cdc42 in the Slit-Robo pathway," Cell, vol. 107, no. 2, pp. 209-221, 2001.

[16] U. Kutay, G. Lipowsky, E. Izaurralde et al., "Identification of a tRNA-specific nuclear export receptor," Molecular Cell, vol. 1, no. 3, pp. 359-369, 1998.

[17] G.-J. Arts, M. Fornerod, and I. W. Mattaj, "Identification of a nuclear export receptor for tRNA," Current Biology, vol. 8, no. 6, pp. 305-314, 1998.

[18] S. Morton, L. Hesson, M. Peggie, and P. Cohen, "Enhanced binding of TBK1 by an optineurin mutant that causes a familial form of primary open angle glaucoma," FEBS Letters, vol. 582, no. 6, pp. 997-1002, 2008.

[19] S. Tommasi, R. Dammann, S.-G. Jin, X.-F. Zhang, J. Avruch, and G. P. Pfeifer, "RASSF3 and NORE1: identification and cloning of two human homologues of the putative tumor suppressor gene RASSF1," Oncogene, vol. 21, no. 17, pp. 2713-2720, 2002.

[20] A. Mok, H. Cao, and R. A. Hegele, "Genomic basis of mucopolysaccharidosis type IIID (MIM 252940) revealed by sequencing of GNS encoding $N$-acetylglucosamine-6sulfatase," Genomics, vol. 81, no. 1, pp. 1-5, 2003.

[21] K. Ishibashi, E. Kanno, T. Itoh, and M. Fukuda, "Identification and characterization of a novel Tre-2/Bub2/Cdc16 (TBC) protein that possesses Rab3A-GAP activity," Genes to Cells, vol. 14, no. 1, pp. 41-52, 2009.

[22] J.-C. Hsieh, L. Kodjabachian, M. L. Rebbert et al., "A new secreted protein that binds to Wnt proteins and inhibits their activites," Nature, vol. 398, no. 6726, pp. 431-436, 1999. 
[23] Z. M. Ahmed, R. Yousaf, B. C. Lee et al., "Functional null mutations of MSRB3 encoding methionine sulfoxide reductase are associated with human deafness DFNB74," The American Journal of Human Genetics, vol. 88, no. 1, pp. 19-29, 2011.

[24] K.-Y. Chau, U. A. Patel, K.-L. D. Lee, H.-Y. P. Lam, and C. CraneRobinson, "The gene for the human architectural transcription factor HMGI-C consists of five exons each coding for a distinct functional element," Nucleic Acids Research, vol. 23, no. 21, pp. 4262-4266, 1995.

[25] A. H. Ligon, S. D. P. Moore, M. A. Parisi et al., "Constitutional rearrangement of the architectural factor HMGA2: a novel human phenotype including overgrowth and lipomas," American Journal of Human Genetics, vol. 76, no. 2, pp. 340348, 2005. 


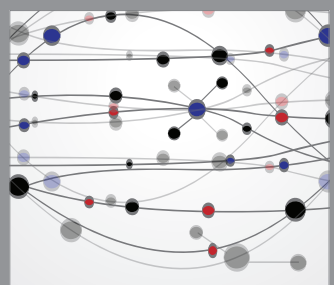

The Scientific World Journal
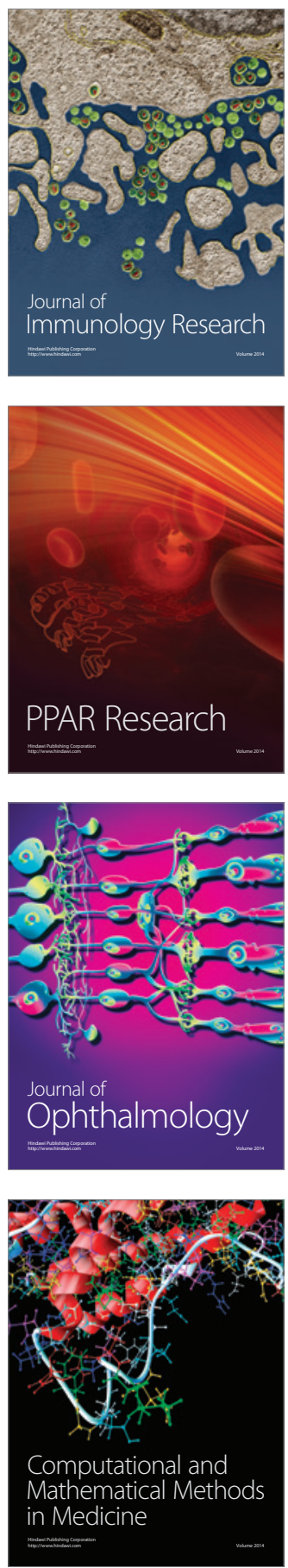

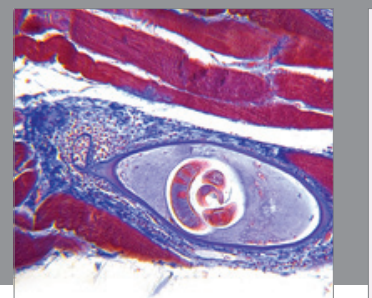

Gastroenterology

Research and Practice
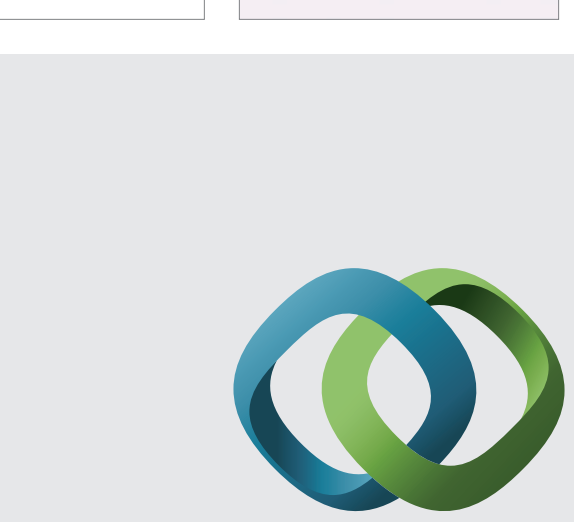

\section{Hindawi}

Submit your manuscripts at

http://www.hindawi.com
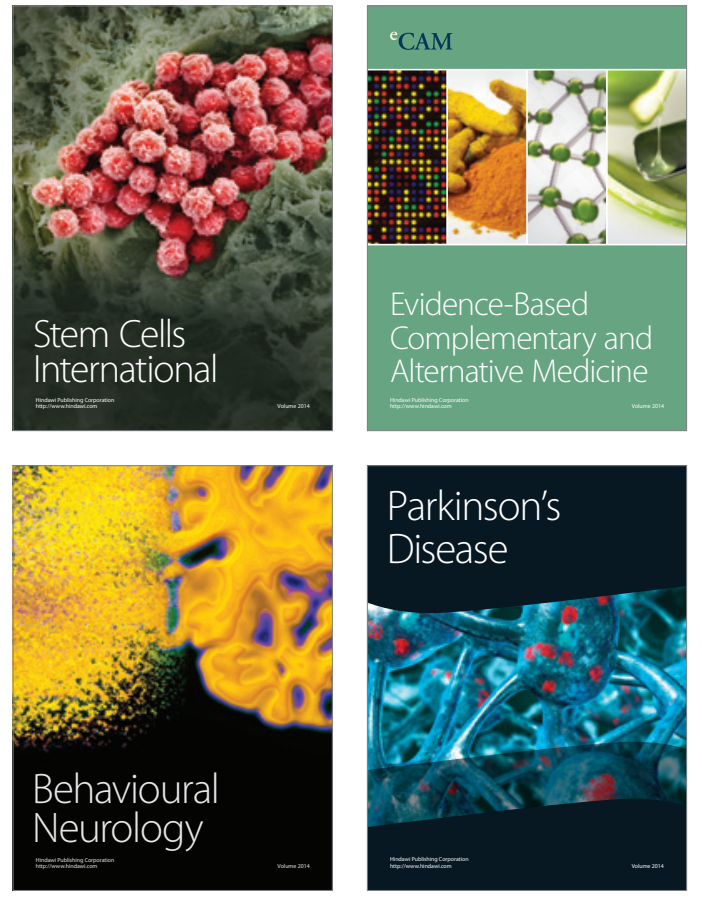
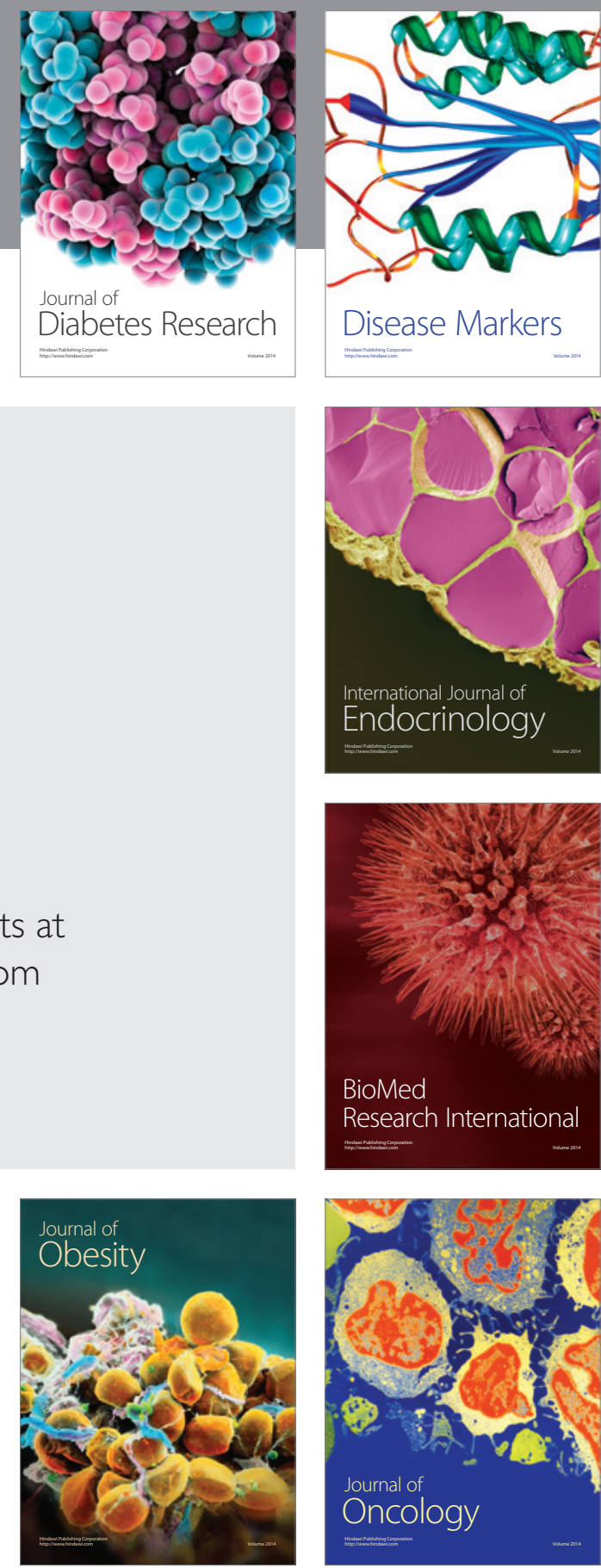

Disease Markers
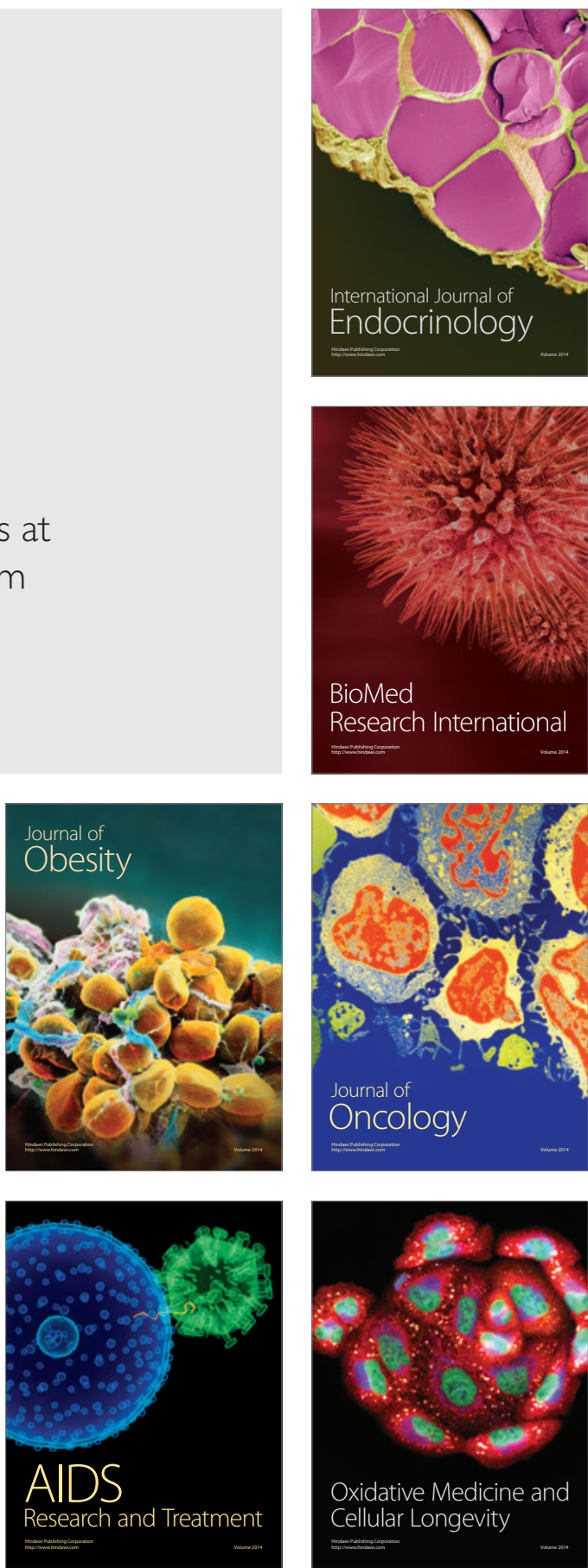